\title{
BALSA ESCOLA: EDUCAÇÃO DE TEMPO INTEGRAL EM UMA ESCOLA LOCALIZADA NO CAMPO EM HUMAITÁ NO ESTADO DO AMAZONAS ${ }^{1}$
}

\author{
Zilda Gláucia Elias FRANCO \\ Eulina Maria Leite NOGUEIRA ${ }^{\text {ii }}$ \\ Saray MARQUES ${ }^{\text {iii }}$
}

\begin{abstract}
RESUMO
Este artigo discute as questões e as possibilidades trazidas pela proposta de tempo integral, no contexto de uma escola do campo da Rede Pública Municipal de Humaitá, município da região sul do Amazonas. A pesquisa teve como objetivo compreender como está organizado o tempo integral nessa unidade escolar e como foi construída a sua proposta curricular. Por meio da abordagem qualitativa, com o apoio da pesquisa de campo, foram aplicados, aos educadores e aos educandos, questionários semiestruturados contendo questões abertas e fechadas. Os resultados apontam que as dificuldades encontradas na escola pesquisada, desde o trajeto de suas casas até a escola, ao acesso aos recursos tecnológicos, dentre outras, são aspectos que interferem no andamento das atividades/do currículo escolar.
\end{abstract}

PALAVRAS-CHAVE: Educação do Campo; Escola de tempo integral; Educação Integral; Currículo.

\section{FERRY SCHOOL: FULL-TIME EDUCATION IN A SCHOOL LOCATED IN THE FIELD IN HUMAITÁ IN THE STATE OF AMAZONAS}

\begin{abstract}
This paper discusses the issues and possibilities brought by the full-time proposal, in the context of a school in the rural area of the Municipal Public Network of Humaitá, a municipality in the southern region of Amazonas, Brazil. The main objective of the research was to understand how full-time is organized in this school unit and how its curriculum proposal was built. Through the qualitative approach, with the support of field research, semi-structured questionnaires containing open and closed questions were applied to educators and students. The results show that the difficulties found in the school researched, starting from the route between their homes and school, to the access to technological resources, among others, are aspects that interfere in the progress of the activities/school curriculum.
\end{abstract}

KEYWORDS: Rural Education; Full-time school; Comprehensive Education; Curriculum.

\footnotetext{
${ }^{\text {i }}$ Doutorado em Educação pela Pontifícia Universidade Católica de São Paulo (PUC-SP). Professora do Instituto de Educação, Agricultura e Ambiente (IEAA) da Universidade Federal do Amazonas (UFAM). E-mail: zildaglaucia@hotmail.com.

ii Doutorado em Educação pela Pontifícia Universidade Católica de São Paulo (PUC-SP). Professora do Instituto de Educação, Agricultura e Ambiente (IEAA) da Universidade Federal do Amazonas (UFAM). E-mail: eulinanog@ hotmail.com.

iii Doutorado em Educação pela PUC-SP. Professora do Instituto Federal de São Paulo (IFSP). Coordenadora Institucional do Programa Residência Pedagógica/CAPES - Professora da Faculdade de São Vicente (FSV). Email: saray.marques@ifsp.edu.br.
} 


\title{
BALSA ESCUELA: EDUCACIÓN A TIEMPO COMPLETO EN UNA ESCUELA UBICADA EN EL CAMPO DE HUMAITÁ EN EL ESTADO DE AMAZONAS
}

\begin{abstract}
RESUMEN
Este artículo discute las cuestiones y las posibilidades traídas por la propuesta de tiempo completo, en el contexto de una escuela en el campo de la Red Pública Municipal de Humaitá, municipio de la región sur de Amazonas, Brasil. La investigación tuvo como objetivo comprender cómo está organizado el tiempo completo en esta unidad escolar y cómo fue construida su propuesta curricular. Por medio del enfoque cualitativo, con el apoyo de la investigación de campo, fueron aplicados cuestionarios semi estructurados conteniendo preguntas abiertas y cerradas a educadores y estudiantes. Los resultados muestran que las dificultades encontradas en la escuela investigada, desde el trayecto de sus casas hasta la escuela, para acceder a los recursos tecnológicos, entre otros, son aspectos que interfieren en el funcionamiento de las actividades/currículum escolar.
\end{abstract}

PALABRAS CLAVE: Educación de campo; Escuela a tiempo completo; Educación integral; Currículum.

\section{INTRODUÇÃO}

O Estado do Amazonas é o maior em área territorial do país, com 1.559.161,682 quilômetros quadrados, e detém um dos mais baixos índices de densidade demográfica, conforme dados do Instituto Brasileiro de Geografia e Estatística (IBGE). A população estimada do Estado, de acordo com o IBGE (2019), é de 4.144.597 habitantes. Com inúmeras vias fluviais, o estado possui patamares de altitude diferenciados de acordo com o volume de águas dos rios. Todas as sedes dos municípios foram estabelecidas ao longo de um rio ou igarapé, dada a sua importância pelo transporte, pelo abastecimento de água e pela pesca.

O contexto em estudo situa-se no município de Humaitá, localizado ao sul do estado do Amazonas. Sua população é de 54.001 habitantes, de acordo com o IBGE (2019). Sua área é de $33.071 .667 \mathrm{~km}^{2}$, um dos maiores em área territorial do estado, e a densidade demográfica, em 2010, era de 1,34 hab/km². Em Humaitá, no universo escolar de 9.094 matrículas no Ensino Fundamental e 2.486 matrículas no Ensino Médio (IBGE, 2018), de acordo com os dados da Secretaria Municipal de Educação (SEMED), tem-se 58 escolas localizadas na área rural, que funcionam atendendo a 3.516 alunos (HUMAITÁ, 2019). Destas, 50 escolas localizam-se nas comunidades, uma escola flutuante/balsa-escola e sete escolas são localizadas próximas à margem da BR 319 (sentido Humaitá - Amazonas/Porto Velho - Rondônia e Humaitá/Manaus - Amazonas) e da BR 230 (sentido Humaitá/Apuí - Amazonas e Humaitá/Lábrea - Amazonas). A Secretaria Municipal de Educação de Humaitá divide as escolas localizadas na zona rural em duas categorias: escolas ribeirinhas e escolas da estrada. 
De acordo com Franco (2018), há duas estações do ano predominantes que interferem no acesso às escolas ribeirinhas e da estrada. "[...] algumas escolas da estrada têm grandes dificuldades na estação chuvosa, conhecida como 'inverno amazônico', período caracterizado por grande volume de chuvas, o que dificulta a entrada às escolas devido às estradas não serem asfaltadas [...]" (FRANCO, 2018, p. 30). Em outro período, o seco (verão amazônico), as equipes da SEMED conseguem atender, de forma mais adequada, às necessidades das escolas; e os professores têm o deslocamento mais rápido. Essa situação diverge das escolas localizadas na área ribeirinha.

Muitas escolas estão localizadas ao longo do Rio Madeira e em igarapés próximos; no entanto, outras escolas ficam dentro de pequenos rios, lagos e igarapés, com acesso restrito no período de vazante dos rios. Essas especificidades da região dificultam a comunicação das escolas com a Secretaria de Educação, dos coordenadores de polo e de professores, bem como o acesso aos materiais necessários para o bom funcionamento das escolas (FRANCO, 2018).

Dentre as escolas localizadas na área rural, está a Escola Municipal Rural Osmarina Melo de Oliveira, comumente conhecida como Balsa Escola ${ }^{2}$. A escola fica atracada às margens do Rio Madeira, em frente à Comunidade São Sebastião do Tapurú e sua implantação ocorreu com o objetivo de atender às necessidades dos alunos do Ensino Fundamental I e II, das comunidades de Perseverança, Marilândia, Miriti, Lavras, Trapiche, Canteiro do Caiarí, Caiarí, São Rafael, São Sebastião do Tapuru, Ilha do Tapuru, Santa Maria, Santa Augusta, São Domingos e Arroizal, bem como a melhoria e a qualidade de ensino (HUMAITÁ, 2016).

A implantação da escola surgiu a partir da maior enchente ocorrida no Rio Madeira no ano de 2014, por via da Lei Municipal $\mathrm{N}^{\circ}$ 679, de 12 de maio de 2015, com o objetivo de substituir as escolas das comunidades de várzea (HUMAITÁ, 2015), pois elas foram alagadas e destruídas, impossibilitando o seu acesso. De acordo com a documentação analisada, as escolas dessas localidades possuíam turmas multisseriadas com alto índice de reprovação e de evasão escolar e que ansiavam por mudanças em função do período de chuvas, visto que muitas escolas ficavam alagadas; além da oportunidade de atendimento aos alunos em turmas seriadas com a expectativa de melhorar o processo de ensino e de aprendizagem.

Assim sendo, este artigo tem como objetivo compreender como está organizado o tempo integral nessa Balsa Escola e como foi construída a sua proposta curricular. Buscamos verificar, junto aos professores e aos alunos, os aspectos administrativos e pedagógicos do ensino em 
tempo integral no contexto de uma escola flutuante. Na perspectiva de atingir tais objetivos, abordamos, a seguir, os caminhos metodológicos que nortearam esta pesquisa. Em seguida, tratamos da Educação Integral e da escola de tempo integral, e por fim, antes das considerações finais, analisamos os dados coletados no contexto da escola investigada.

\section{PROCEDIMENTOS METODOLÓGICOS}

Optamos, nesta pesquisa, pela abordagem qualitativa, que, segundo Triviños (1987), auxilia na compreensão de realidades complexas, uma vez que se pode adotar o procedimento da pesquisa participante, na qual o pesquisador tem ampla liberdade metodológica para realizar seu estudo e compreender os indivíduos participantes da investigação delimitada. Assim sendo, os dados coletados foram anotados e, posteriormente, descritos e analisados à luz da pesquisa qualitativa.

Com a finalidade de aprofundar nossos conhecimentos sobre o tema da investigação, iniciamos por uma pesquisa de natureza exploratória que, no entender de Triviños (1987, p. 94), visa à "[...] conscientização, tanto do pesquisador, como dos integrantes do grupo social, dos problemas que existem, das dificuldades que se apresentam, e do interesse coletivo [...]". Dessa maneira, utilizando a pesquisa bibliográfica, buscamos informações sobre a Balsa Escola como alternativa para o atendimento aos estudantes do campo, o ensino em tempo integral e a proposta curricular adotada pela instituição de ensino, conhecimentos fundamentais para subsidiar a análise dos resultados obtidos com a observação, as entrevistas (diálogos) e a aplicação do questionário, tendo em vista a orientação de Chizzotti (2000). Segundo o autor: "A aplicação dos instrumentos de pesquisa requer um trabalho planejado para prever os procedimentos que serão adotados, as circunstâncias em que deverão ocorrer, a fim de controlar a incidências variáveis" (CHIZZOTTI, 2000, p. 45).

Para a análise dos dados levantados, tomamos como base as leituras dos títulos escolhidos, utilizando, como temas-chave, a Educação do Campo, a Balsa Escola e o ensino em tempo integral. Para melhor compreensão dos resultados obtidos, aplicamos a Análise de Conteúdo, por meio de procedimentos ordenados e objetivos de descrição de conteúdo e a dedução com relação à produção e à recepção dessas informações (BARDIN, 2004).

Para o desenvolvimento deste estudo, utilizamos: a pesquisa bibliográfica e de campo, por meio da observação in locus, da aplicação de questionário aos professores atuantes nessa 
instituição e de entrevistas (diálogos) com parte dos alunos e com a Secretária Municipal da Educação de Humaitá.

\section{CURRÍCULO E EDUCAÇÃO DO CAMPO: SUPERAÇÃO DE DESIGUALDADES E AFIRMAÇÃO DAS DIFERENÇAS}

A Educação do Campo ocorre em espaços denominados rurais: em todo espaço educativo situado em locais como florestas, agropecuária, agricultura, além dos espaços pesqueiros, das populações ribeirinhas, caiçaras e extrativistas. Recebe, também, essa denominação a educação ofertada para comunidades quilombolas, em assentamentos ou em áreas indígenas. Tendo em vista a realidade de cada uma das regiões e localidades em que essa educação se desenvolve, seus currículos devem se adequar à valorização da cultura e do fazer da população a que se destina, de maneira a preservar seus usos e costumes, bem como sua diversidade e sua dedicação ao campo, como preconiza o Decreto $\mathrm{N}^{\circ} 7.352$, de 4 de novembro de 2010, que explicita, no Art. 1: "A política de Educação do Campo destina-se à ampliação e qualificação da oferta de educação básica e superior às populações do campo" (BRASIL, 2010a, p. 1) em regime de colaboração entre entes federativos e as diretrizes e as metas estabelecidas no Plano Nacional de Educação (PNE).

O mesmo Decreto, em seu artigo $2^{\circ}$, estabelece os princípios da Educação do Campo:

I - respeito à diversidade do campo em seus aspectos sociais, culturais, ambientais, políticos, econômicos, de gênero, geracional e de raça e etnia; II - incentivo à formulação de projetos político-pedagógicos específicos para as escolas do campo, estimulando o desenvolvimento das unidades escolares como espaços públicos de investigação e articulação de experiências e estudos direcionados para o desenvolvimento social, economicamente justo e ambientalmente sustentável, em articulação com o mundo do trabalho; III - desenvolvimento de políticas de formação de profissionais da educação para o atendimento da especificidade das escolas do campo, considerando-se as condições concretas da produção e reprodução social da vida no campo; IV - valorização da identidade da escola do campo por meio de projetos pedagógicos com conteúdos curriculares e metodologias adequadas às reais necessidades dos alunos do campo, bem como flexibilidade na organização escolar, incluindo adequação do calendário escolar às fases do ciclo agrícola e às condições climáticas;

$\mathrm{V}$ - controle social da qualidade da educação escolar, mediante a efetiva participação da comunidade e dos movimentos sociais do campo (BRASIL, 2010a, p. 1). 
Nem sempre esse pressuposto legal tem sido colocado em prática. Nesse sentido, Caldart (2002, p. 22) pontua que “[...] não há como verdadeiramente educar os sujeitos do campo sem transformar as circunstâncias sociais desumanizantes, e sem prepará-los para serem os sujeitos destas transformações". Mais do que colocar à disposição da população escolas próximas aos seus locais de moradia, é necessário compreender que a Educação do Campo visa à construção de sujeitos críticos, conscientes de sua condição na sociedade e capazes de lutar pela conquista e garantia dos direitos dos camponeses, com o intuito de construir uma sociedade mais justa, frente a um sistema reprodutor de desigualdades econômicas e sociais como no Brasil. Essa concepção somente se tornará realidade quando a escola oferecer currículos que levem em conta a realidade vivenciada por esses sujeitos, a fim de que possam entendê-la e buscar sua transformação.

Entendemos que o currículo escolar deve ser vinculado ao projeto de sociedade que possibilite a superação das desigualdades e afirmação das diferenças, tornando-se, assim, uma ferramenta importante na promoção social de alunos e de suas famílias. O currículo faz parte de um campo de discussão de professores, pesquisadores e do dia a dia da escola, um instrumento essencial carregado por questionamentos sobre o ensinar, como ensinar, de que forma deverá ser construído esse conhecimento. É a organização da prática pedagógica que envolve vários sujeitos e diferentes práticas políticas, sociais, econômicas, de produção, meios didáticos e de controle (PONCE; FRANCO, 2017). Nesse sentido, podemos afirmar que o currículo não é neutro, perpassa por diversos interesses e se localiza na arena da disputa do "consenso" de um tipo de sociedade. A perspectiva de Escola do Campo deve ser pautada em construir a autonomia do indivíduo em comunidade; a preparação para viver e (re)criar a vida, valorizando o conhecimento por meio do convívio democrático, que insira o sujeito no mundo do trabalho. Assim, o currículo pode tornar-se um instrumento de consistência dos educandos com a coletividade da qual faz parte por meio de um todo democrático e solidário com igualdade de oportunidades, respeitando suas diversidades (DUBET, 2008).

Foram muitos os avanços democráticos em relação à educação escolar do início do século XXI, expressos pela busca da universalização, pelas políticas afirmativas e de promoção de igualdades. Contudo, ainda há muito a se fazer em direção à construção de um currículo que contemple a diferença, a justiça social e a igualdade de direitos e deveres. É necessário pensar o currículo de forma ampla e abrangente, na compreensão de que o "[...] currículo abarca a vida mesma da escola, o que nela se faz ou não se faz, as relações entre todos e todas que fazem a 
escola" (FREIRE, 2005, p. 123) - um currículo que demonstre a força das ideias como prática concreta.

A produção do conhecimento é constituída a partir de uma inter-relação complexa de diferentes contextos. Entende-se, então, que o currículo deve ser envolvido aos conteúdos, moderado por diálogo de conhecimentos e de procedimentos de formação (PIRES, 2012). Os saberes e as experiências dos povos do campo, seus movimentos e todo trabalho produzido por eles como forma de socializar o saber corroboram para que compreendam sua realidade e as relações (ARROYO, 1999, 2011). Desse modo, organizar o currículo escolar é a forma de mostrar os saberes do campo em vista de pensar a realidade de cada localidade, antecipando muito mais do que a escolha e a organização dos conteúdos. A Escola do Campo deve levar em consideração a resistência, as ações promovidas pelos seus movimentos coletivos, de modo a reconhecer esses processos e sua rica diversidade como direito ao conhecimento, incorporandoos nos currículos.

Nesse sentido, o currículo é formado por contextos trazidos para dentro da escola pelos diferentes sujeitos que a constituem e passa a fazer parte de outros contextos desses mesmos sujeitos. Dessa forma, o currículo passa a ser o que é praticado pelos sujeitos nos diversos espaços e tempos dos quais fazem parte.

\section{REPENSANDO A EDUCAÇÃO INTEGRAL E A ESCOLA DE TEMPO INTEGRAL}

A expressão "Educação Integral” surgiu no final do século XIX e início do século XX, como uma forte reação à pedagogia tradicional, com fundamentos na visão humanista de valorização do sujeito e de desenvolvimento de suas potencialidades em várias dimensões (física, afetiva, intelectual, social, moral, estética), a fim de que fosse possível formar homens capazes de compreender o mundo em que vivem para, então, fazerem intervenções e promoverem o bem comum e a convivência solidária. De acordo com Gonçalves (2006):

O conceito mais tradicional encontrado para a definição de educação integral é aquele que considera o sujeito em sua condição multidimensional, não apenas na sua dimensão cognitiva, como também na compreensão de um sujeito que é sujeito corpóreo, tem afetos e está inserido num contexto de relações. Isso vale dizer a compreensão de um sujeito que deve ser considerado em sua dimensão bio-psicossocial. [...] o sujeito multidimensional é um sujeito desejante, o que significa considerar que, além da satisfação de suas necessidades básicas, ele tem demandas simbólicas, busca satisfação nas suas diversas formulações de realização, tanto nas 
atividades de criação quanto na obtenção de prazer nas mais variadas formas. (GONÇALVES, 2006, p. 130).

Em consonância com essa citação, Gonçalves (2006) afirma que só faz sentido pensar na ampliação da jornada escolar, na implantação das escolas de tempo integral, se considerarmos uma Educação Integral que represente uma ampliação de conhecimentos e que promova aprendizagens significativas.

A ampliação do tempo dos estudantes na escola tem sido uma das opções para a melhoria da preparação integral das crianças e dos jovens; no entanto, conforme posicionamento do Observatório do PNE (2018), “[...] é importante considerar que Educação Integral não é sinônimo de mais tempo na escola, apenas [...] é preciso propiciar múltiplas oportunidades de aprendizagem por meio do acesso à cultura, à arte, ao esporte, à ciência e à tecnologia”. Em relação ao exposto, Cavaliere (2006, p. 95) diz-nos:

No caso brasileiro, o que poderia efetivamente colocar a ampliação do tempo escolar a serviço da emancipação seria a compreensão dessa ampliação como condição para a incorporação de uma nova lógica de organização do tempo: um tempo que propicie vivências multidimensionais, não comprimidas numa grade horária padronizada e esterilizante. Dessa forma, certos tipos de experiências e saberes que normalmente não frequentam as escolas - mas que são fundamentais tanto aos processos individuais quanto coletivos de emancipação, ou seja, saberes e práticas normalmente presentes em contexto familiares ou privados - poderiam penetrar com sucesso nas escolas.

No contexto brasileiro, a Lei de Diretrizes e Bases (LDB) - Lei No 9.394, de 20 de dezembro de 1996 -, em seu artigo $2^{\circ}$, embora não a mencione, faz referência a preceitos associados à concepção de Educação Integral: “A educação, dever da família e do Estado [...], tem por finalidade o pleno desenvolvimento do educando, seu preparo para o exercício da cidadania e sua qualificação para o trabalho" (BRASIL, 1996, n.p., grifo nosso). Esse pressuposto legal fundamenta a oferta de educação que, para além do ensino da leitura, escrita e cálculo, leva em conta a formação humana dos sujeitos, possibilitando-lhes a participação cidadã com vistas à transformação social.

A LDB de 1996 estabelece também, em seu Artigo 34, que a “[...] jornada escolar no ensino fundamental incluirá pelo menos quatro horas de trabalho efetivo em sala de aula, sendo progressivamente ampliado o período de permanência na escola”. No $\S 2^{\circ}$, do mesmo artigo, estabelece-se que: "O ensino fundamental será ministrado progressivamente em tempo integral, a critério dos sistemas de ensino" (BRASIL, 1996, n.p.). 
Considerando-se a necessidade de reestruturação do papel da escola e da educação, no âmbito de políticas sociais que motivem mudanças e novos olhares sobre a função educacional da escola, surge o PNE, promulgado pela Lei $\mathrm{N}^{\circ} 13.005$, de 25 de junho de 2014. A Meta 6 da referida Lei faz referência à educação de tempo integral, cujo objetivo é "[...] oferecer educação em tempo integral em, no mínimo, 50\% (cinquenta por cento) das escolas públicas, de forma a atender, pelo menos, $25 \%$ (vinte e cinco por cento) dos (as) alunos (as) da educação básica" (BRASIL, 2014, p. 3). Essa meta define o tempo do aluno na escola, que não se constitui neutro, pois tempo e espaço abrigam ações que expressam o que acontece cotidianamente no ambiente escolar.

O currículo do ensino em tempo integral carece contemplar não apenas os conhecimentos historicamente construídos pela humanidade, mas também aqueles saberes formadores de cidadãos críticos, conscientes, participativos e capazes de exercer o papel que lhes cabe na sociedade, na perspectiva da transformação social, ambiental e humana. Nesse sentido, segundo Marques (2017, p. 22): "Não se pode pensar em ampliação de tempo e espaço escolar sem se proceder à reflexão sobre o currículo e sobre os impactos das mudanças na organização escolar".

Para além desses conhecimentos, o currículo do ensino em tempo integral necessita valorizar o desenvolvimento das crianças e dos jovens por meio do acesso às artes, aos esportes, às atividades que promovam a criatividade, ao trabalho em equipe, à formação de liderança e ao empreendedorismo, sem se esquecer das raízes étnico-culturais dos povos do campo.

\section{CONTEXTO DA ESCOLA MUNICIPAL RURAL OSMARINA MELO DE OLIVEIRA}

De acordo com o documento referente à embarcação (HUMAITÁ, 2014), a Escola Municipal Rural Osmarina Melo de Oliveira foi construída no ano de 2014 e recebeu a designação de Base Educacional Irmã Angelica Tonetta. Esse modelo de Escola Balsa (Figura 1) possui 19.000 toneladas de peso bruto, com comprimento total de 30.950 metros, sendo o casco, os conveses, as superestruturas, as casarias construídas em aço, podendo alocar 160 pessoas.

A embarcação é composta por um convés principal, o primeiro e o segundo conveses. Um motor trifásico a diesel distribui toda energia, não possuindo equipamentos de rádio nem 
de emergência, apenas boias e coletes salva-vidas simples.

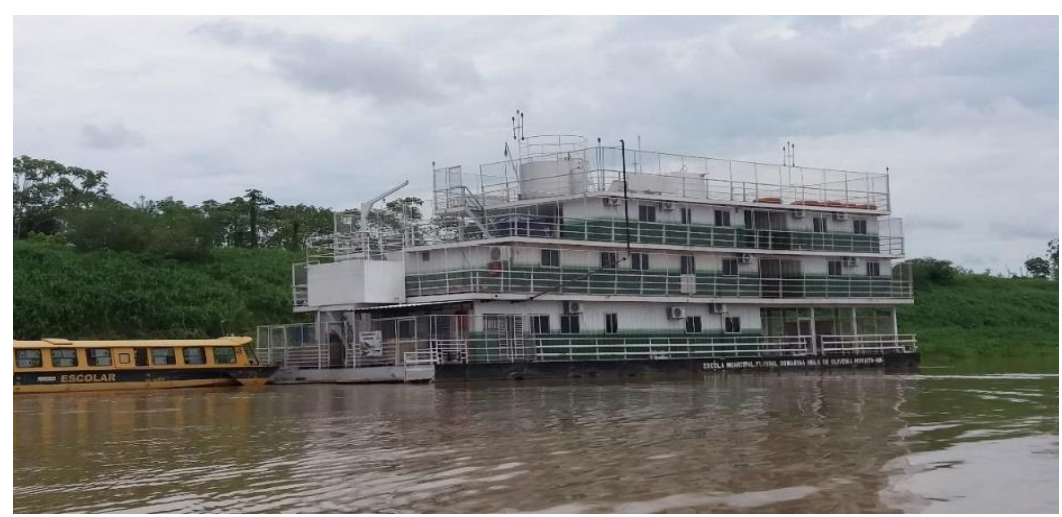

Figura 1 - Escola Municipal Rural Osmarina Melo de Oliveira Fonte: Franco (2018, p. 95).

Ainda com relação ao aspecto físico da Balsa Escola, no convés principal, onde fica a entrada (espaço também de armazenamento de galões de água - a embarcação não possui um sistema de tratamento de água), situam-se o refeitório, as salas de aula, a sala da enfermagem (onde a enfermeira atende a pessoas das comunidades próximas), o motor da embarcação e o armazenamento do diesel que abastece o motor.

No total, são nove salas de aulas, uma sala dividida entre a Educação Infantil e o $1^{\circ}$ Ano do Ensino Fundamental (dividida por paredes de PVC), quatro salas de aula destinadas aos anos iniciais do Ensino fundamental I ( $2^{\circ}$ ao $5^{\circ}$ ano), e quatro salas para o Ensino fundamental II. No primeiro convés, há salas de aulas, dormitórios, banheiros, sala de informática (com computadores, porém não há acesso à internet), sala da direção e secretaria (usada como sala de aula por falta de espaço). O segundo convés possui mais salas de aula, cozinha e dormitórios, um espaço para os embarcados fazerem suas refeições e um banheiro. Na parte superior da embarcação, fica toda instalação do gás. O acesso de um convés para o outro é feito por escadas. A Figura 2 mostra essa estrutura. 

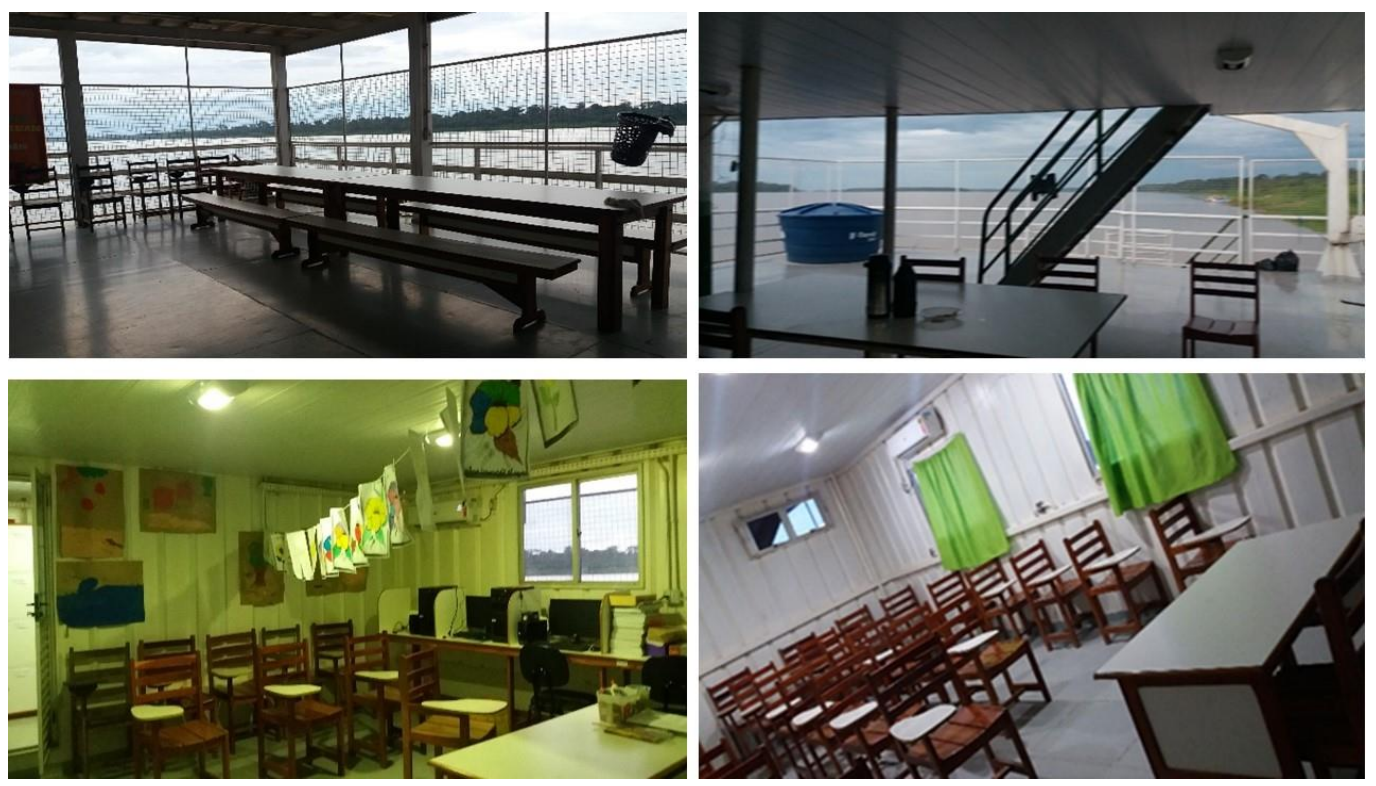

Figura 2 - Estrutura física da escola

Fonte: Acervo das autoras.

A escola atende a educandos desde a Educação Infantil até o $9^{\circ}$ ano do Ensino Fundamental. Os dados coletados na pesquisa mostram que, no ano de 2016, havia 164 matrículas ${ }^{3}$; em 2017, 145 estudantes foram matriculados; em 2018, 172 alunos; e, no ano de 2019, foram efetivadas 175 matrículas. As turmas são seriadas; entretanto, devido à falta de espaço, as salas da Educação Infantil e do $1^{\circ}$ ano do Ensino Fundamental ficam juntas e contam com dois professores que trabalham os conteúdos específicos de cada nível e ano.

A embarcação oferece o serviço de enfermaria em uma sala própria, com uma enfermeira. Seu corpo de profissionais é constituído por 17 pessoas, sendo 12 professores (conforme mostra o Quadro 1, entre eles o gestor) e cinco auxiliares (duas cozinheiras, dois profissionais de serviços gerais e um piloto). A Balsa Escola não possui pedagogo (no município ele representa a figura do coordenador escolar) e nem a secretaria escolar (referenciadas no regimento escolar-2017).

Quadro 1 - Quadro de educadores da Escola Municipal Rural

Osmarina Melo de Oliveira (2017)

\begin{tabular}{|l|l|l|l|l|l|}
\hline & \multicolumn{1}{|c|}{ Função } & \multicolumn{1}{|c|}{ Formação } & $\begin{array}{c}\text { Tempo de } \\
\text { atividade } \\
\text { na escola }\end{array}$ & Onde mora? & $\begin{array}{c}\text { Turma que } \\
\text { trabalha/projeto }\end{array}$ \\
\hline 1 & Educador & Letras & 1 ano & Humaitá-Balsa & $\begin{array}{l}6^{\circ} \text { ao } 9^{\mathbf{0}} \text { ano } \\
\text { Língua Portuguesa }\end{array}$ \\
\hline 2 & Educadora & Normal Superior & 2 anos & Rio Madeira - & Jardim I e II \\
\hline
\end{tabular}




\begin{tabular}{|c|c|c|c|c|c|}
\hline & Função & Formação & $\begin{array}{l}\text { Tempo de } \\
\text { atividade } \\
\text { na escola }\end{array}$ & Onde mora? & $\begin{array}{c}\text { Turma que } \\
\text { trabalha/projeto }\end{array}$ \\
\hline & & & & Sítio Santa Luzia & \\
\hline 3 & Educador & $\begin{array}{l}\text { Geografia } \\
\text { Curso de Letras }\end{array}$ & 1 ano & Humaitá-Balsa & $\begin{array}{l}6^{\circ} \text { ao } 9^{\circ} \text { ano } \\
\text { Matemática }\end{array}$ \\
\hline 4 & Educador & Normal Superior & 2 anos & $\begin{array}{l}\text { Rio Madeira - } \\
\text { Trapicho }\end{array}$ & $1^{\circ}$ ano \\
\hline 5 & Gestor & Pedagogia & 1 ano & Humaitá-Balsa & Gerenciamento \\
\hline 6 & Educadora & Pedagogia & 2 anos & Humaitá-Balsa & $2^{\circ}$ ano \\
\hline 7 & Educadora & Contabilidade & 1 ano & $\begin{array}{l}\text { Rio Madeira - } \\
\text { Comunidade São } \\
\text { Rafael }\end{array}$ & $\begin{array}{l}6^{\circ} \text { ao } 9^{\circ} \text { ano } \\
\text { História, Artes e } \\
\text { Religião }\end{array}$ \\
\hline 8 & Educadora & Pedagogia & 1 ano & Porto Velho-Balsa & $3^{\circ}$ Ano \\
\hline 9 & Educadora & $\begin{array}{ll}\text { Letras } & - \\
\text { Cursando } & \\
\text { Geografia } & \text { e } \\
\text { História } & \\
\end{array}$ & 1 ano & Humaitá-Balsa & $\begin{array}{l}6^{\circ} \text { ao } 9^{\circ} \text { ano } \\
\text { Informática, } \\
\text { Inglês e Geografia }\end{array}$ \\
\hline 10 & Educador & Normal Superior & 2 anos & Humaitá-Balsa & $5^{\circ}$ ano \\
\hline 11 & Educadora & Pedagogia & 1 ano & Humaitá-Balsa & $4^{\circ}$ ano \\
\hline 12 & Educadora & Pedagogia & 6 meses & Humaitá-Balsa & $\begin{array}{l}6^{\circ} \text { ao } 9^{\circ} \text { ano } \\
\text { Ciências }\end{array}$ \\
\hline
\end{tabular}

Fonte: Elaborado pelas autoras com base no diário de campo de Franco (2018).

Ao analisarmos o perfil dos professores que trabalham na Balsa Escola, identificamos que alguns não atendem ao que diz a LDB, no artigo 62, com relação ao professor que necessita trabalhar na sua área de formação. $\mathrm{O}$ corpo docente possui educadores que atendem às disciplinas de Artes, História, Religião, Matemática e Informática, que não são formados nessas áreas específicas, porém se instrumentalizam para dar conta da demanda. A Balsa Escola não possui um pedagogo para acompanhar e orientar as diversas atividades. Entende-se que esse fato pode comprometer o desenvolvimento do processo de aprendizagem, pois "[...] é inerente ao trabalho do pedagogo, diante de sua responsabilidade social, a mediação indispensável entre produção do conhecimento e a organização sistemática dos processos de ensino-aprendizagem, para a formação dos estudantes” (BRUNO; FORTUNATO; MESQUIDA, 2011, p. 3973).

Oito desses professores não residem nas comunidades próximas e moram na embarcação, três residem em comunidades próximas à escola e vêm com os alunos para as aulas e um reside em outro Estado, Rondônia, e possui alojamento na escola. Alguns desses professores não são concursados, possuem apenas contrato temporário com a Prefeitura. A contratação, sem concurso público, fragiliza o cumprimento dos dias letivos contidos entre os meses de março e novembro de cada ano, promovem a rotatividade dos profissionais, a perda de garantias trabalhistas e previdenciárias, provocando instabilidade e precariedade do emprego 
no magistério público (OLIVEIRA, 2004).

De acordo com os dados de seu regimento interno da Balsa Escola (2017), o horário de funcionamento em tempo integral ocorre das 8 horas da manhã às 3 horas e 30 minutos da tarde, conforme mostra o Quadro 2, cujo tempo é dividido em duas etapas.

Quadro 2- Distribuição das atividades durante o dia

\begin{tabular}{|c|c|}
\hline Horário & Atividades \\
\hline 8h às 12h & Aulas do Ensino Fundamental I: matriz curricular \\
\hline 8h30min às 11h30min & Ensino Fundamental II: atividades extracurriculares \\
\hline 11h30min às 12h & Almoço do Ensino Fundamental II \\
\hline 12h às 12h30min & Almoço do Ensino Fundamental I \\
\hline 12h às 15h30min & Aulas do Ensino Fundamental II: matriz curricular \\
\hline 12h30min às 15h30min & Ensino Fundamental I: atividades extracurriculares \\
\hline
\end{tabular}

Fonte: Elaborado pelas autoras com base no diário de campo de Franco (2018).

A embarcação não possui espaço (área livre) para que os alunos possam realizar atividades recreativas ou atividades específicas nas aulas de Educação Física; além disso, não possui biblioteca. O pequeno acervo de livros são expostos em pequenos espaços nas salas de aulas, em sua maioria, apenas nas turmas do Ensino Fundamental I.

Além de entender o contexto da Escola Municipal Rural Osmarina Melo de Oliveira, único espaço educacional em Balsa Escola do país, que atende a crianças e a jovens do Ensino Fundamental I e II e a uma turma de Educação Infantil, procuramos compreender como está organizado o tempo integral na unidade escolar e como foi construída a sua proposta curricular no contexto da escola flutuante. A análise de todo o percurso construído, até o momento, pela Balsa Escola, por meio das atividades desenvolvidas com os professores, das atividades de campo e dos diálogos produzidos com os educadores, permitiu-nos identificar que sua inserção na comunidade do campo ocorreu a partir de um projeto construído diante de "dificuldades apontadas por gestores", que são muito comuns às escolas do campo, mesmo com toda legislação que ampara esses espaços: salas multisseriadas, espaço físico, evasão escolar e nucleação.

O "projeto" de tempo integral na Balsa Escola foi iniciado a partir da criação de um espaço escolar dentro da embarcação, porém sem a elaboração de um currículo pensado com toda a comunidade escolar. Nesse sentido, de acordo com o documento Planejando a próxima década: conhecendo as 20 metas do Plano Nacional de Educação (BRASIL, 2014b), 
[...] garantir educação integral requer mais que simplesmente a ampliação da jornada escolar diária, exigindo dos sistemas de ensino e seus profissionais, da sociedade em geral e das diferentes esferas de governo não só o compromisso para que a educação seja de tempo integral, mas também um projeto pedagógico diferenciado, a formação de seus agentes, a infraestrutura e os meios para sua implantação (BRASIL, 2014b, p. 28).

Consideramos que, para que haja uma educação integral de fato, é necessária a participação efetiva da comunidade escolar, para que contribuam com a ampliação do tempo escolar e construam, de forma coletiva, os documentos legais da escola: Projeto Político Pedagógico e Currículo Escolar que criem oportunidades para que o espaço se transforme em oportunidades e formação das crianças e jovens que ali se encontram, na perspectiva de uma educação integral de formação humana, para que assim possam construir com uma identidade autônoma capaz de transformar a realidade em que vivem. Os dados obtidos mostraram que há uma único PPP para todas as escolas do campo do município.

O currículo escolar associado à Educação Integral não está presente na Balsa Escola, de acordo com os documentos analisados e com a fala do Gestor: "Não temos um histórico da escola. Nem um projeto da educação integral" (Gestor, diário de campo, 2017).

A formação inicial e continuada para os envolvidos no "projeto" da Balsa Escola proposta como de Educação de Tempo Integral ainda não ocorreu até os dias atuais. Os educadores, até o momento, não receberam formação especial para trabalhar com as especificidades que o projeto impõe e faltam recursos necessários básicos à sua implantação. "Em primeiro lugar a gente deveria saber o que é uma escola de tempo integral. Nunca tivemos a formação para isso. A gente faz o possível. Precisamos de informações sobre a temática" (Educador E, diário de campo, 2017).

A escola tinha, como fundamentos iniciais (Programação Anual Balsa Escola de 2016), oferecer aos alunos cursos de violão, de inglês, de informática, criar uma horta e valorizar a cultura local em que os educandos estão inseridos. O projeto foi implantado em partes. A pequena horta foi construída em 2017, em galões de plástico reutilizáveis na própria embarcação, com os recursos próprios do gestor e com o auxílio de uma turma de alunos. As aulas de violão ainda não foram possíveis devido ao fato de não terem um professor para realizar tal atividade. O laboratório de informática existe no espaço (com poucos computadores, mas o suficiente), porém não há um projeto ou um profissional da área que possa atender aos alunos. 
Na prática, os educadores ficam com as turmas em tempo integral no espaço escolar. Em um dos períodos com as atividades da série/turma e no contraturno, desenvolvem-se atividades extracurriculares referenciadas no regimento interno da escola. De acordo com o gestor:

No início, os professores trocavam de turmas no contraturno, um trabalhava matemática, outro leitura, de acordo com as afinidades, faziam projeto. Mas, isso já parou um pouco por falta de interesse deles mesmos de fazer o projeto. Assim, à tarde, permanecem com os mesmos professores. Como os alunos têm muita dificuldade em leitura, todos os professores fizeram algo, de acordo também com suas áreas. O professor de matemática faz um projeto, o de português outro e assim vai. (Gestor, diário de campo, 2017).

Os educadores relataram que só são realizadas atividades ao ar livre durante as aulas de Educação Física. O espaço físico da escola não comporta as atividades de forma adequada, obrigando-os a utilizar o pátio aberto de uma comunidade próxima. "A gente determinou que quem é do primeiro convés fica lá (6 $6^{\circ}$ ano, Educação Infantil e $1^{o}$ ano), não tem acesso lá pra cima. Aqui do meio só tem acesso para almoçar e lanchar. Quem é de cima, $4^{o}$ e $5^{\circ}$ anos ficam aqui. Quem é lá debaixo fica lâ" (Gestor, diário de campo, 2017).

A cada 15 dias os alunos são levados para a comunidade mais próxima, em uma sextafeira, para realizar atividades físicas que envolvem gincanas e brincadeiras, com um lanche diferenciado, tornando o dia mais atrativo e favorecendo o contato com a cultura local. Ao término da manhã, eles retornam à escola para tomar banho e almoçar.

Um dos desafios observados pela pesquisa refere-se ao planejamento que acontece de forma individual, sem a coletividade tão representativa na Educação do Campo e da necessidade da interdisciplinaridade que a Educação Integral pressupõe no desenvolvimento do currículo escolar. De acordo com o relato dos professores, o planejamento é feito bimestralmente. Não possuem biblioteca, fazem pesquisas quando vão à área urbana e fazem contação de histórias com os poucos livros que a escola possui. "Não temos um momento do planejamento, o tempo é individual e há uma cobrança muito grande, não é inerente ao professor [...]. Tem aquela concepção de pegar o livro e... não tem um momento em pensar e quer que a criança aprenda se limitando apenas a quadro, caderno e pincel" (Gestor, diário de campo, 2017).

Ser professor na escola de tempo integral do campo pressupõe compreender aspectos legais e pedagógicos da escola do/no campo, exige do professor "[...] disposição, envolvimento 
e curiosidade, de modo que perceba as potencialidades interventivas e proporcione aos educandos aulas atrativas e com aplicabilidade prática" (TIRONI; GOMES, 2013, p. 5530).

Relatos dos profissionais envolvidos na pesquisa realizada fazem-nos inferir que, na Balsa Escola, não há uma escola integral de fato, como rege o PNE de 2018. Em entrevistas, os professores demonstram a preocupação com aspectos importantes do currículo e das atividades desenvolvidas pelos alunos em casa/no campo: “A realidade de alguns alunos no final de semana é de ajudar os pais no trabalho e também brincar. $70 \%$ dos alunos não trazem tarefa. Como trazer os pais para a escola? O transporte escolar traz os pais para a reunião e eles mandam o tio, o parente" (EDUCADOR E, diário de campo, 2017). "Dificuldade com as tarefas escolares. Eles saem de casa muito cedo. Acordam quatro e meia da manhã, chegam em casa à noitinha e não há como fazer as tarefas. Assim só enviamos nos finais de semana e, mesmo assim, os pais não ajudam (EDUCADOR B, diário de campo, 2017). Os aspectos apontados pelos professores são confirmados pelos alunos: "Por volta do meio-dia, a gente sente muito sono e molha o rosto, brincamos, conversamos com os colegas" (EDUCANDO, diário de campo, 2017).

As questões apresentadas são importantes para reflexão. Os alunos passam o dia todo na escola, levantam-se muito cedo, ainda "à noitinha". Quando chegam as suas casas, como realizar tarefas escolares? A escola, de tempo integral, necessita garantir espaço dentro do currículo para a realização das atividades que possam auxiliar nas disciplinas do currículo escolar. Esse aspecto está amparado nas Diretrizes Operacionais para a Educação Básica nas Escolas do Campo, no Art. 7: “É de responsabilidade dos respectivos sistemas de ensino [...] regulamentar as estratégias específicas de atendimento escolar do campo e a flexibilização da organização do calendário escolar, salvaguardando, nos diversos espaços pedagógicos e tempos de aprendizagem" (BRASIL, 2002, p. 32).

As atividades desenvolvidas pelos alunos, juntamente aos seus pais, fazem parte de suas rotinas. Desde pequenos, esses alunos auxiliam no trabalho do campo, suas famílias vivem da terra, alternando os tempos de plantar e de colher e o tempo escolar, que, em muitos momentos, choca-se com o tempo do trabalho. Segundo Arroyo (2006, p. 114), “[...] as formas de vinculação da infância à agricultura familiar exigem outras formas específicas de organização da escola”.

Pelas observações realizadas na atividade de campo, identificou-se que os alunos se levantam muito cedo para chegar à escola; eles têm, no máximo, 30 minutos de intervalo para 
o almoço e retornam para as salas de aulas por mais 30 minutos e ficam conversando, não há outro espaço para ficarem. O espaço das salas é pequeno. Os alunos e os professores convivem com o calor, caso o ar-condicionado seja desligado, pois a balsa foi construída com um material que não é apropriado para salas de aula.

A Balsa Escola, inicialmente construída pela questão das enchentes associada à política de nucleação das escolas e do transporte escolar, agrega estudantes de diversas escolas/comunidades que chegam até ela por meio de barcos que saem das diversas comunidades, trazendo alunos e professores. O problema da seca no Rio Madeira, em alguns meses do ano, impede o transporte dos alunos (os barcos não conseguem trafegar), mostrando que, antes o problema era das enchentes, e, na Balsa Escola, muitas vezes, são impedidos de chegar à escola em função da seca no rio. ${ }^{4}$

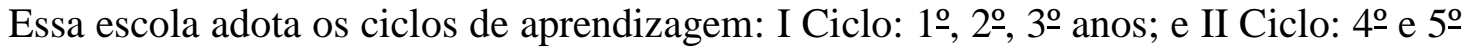
anos. Essa forma de organização contempla a avaliação feita ao longo do ciclo e não ao fim do ano letivo. O sistema de ciclos tem embasamento no regime de promoção continuada, uma perspectiva pedagógica em que a vida escolar e o currículo são assumidos e trabalhados em dimensões de tempo mais flexíveis. Dessa forma, o aluno só poderia ser reprovado no fim de cada ciclo. Os relatos dos professores demonstraram que ainda há um número elevado de distorção idade/série, que são trabalhados por todos para a sua superação.

No contexto da pesquisa, na Escola Municipal Rural Osmarina Melo de Oliveira, a concepção de Educação Integral também pressupõe a ideia de uma oferta maior de oportunidades de complementação para a formação e enriquecimento curricular. Não se trata de um simples aumento quantitativo de horas, mas, sim, de um aumento qualitativo, pois nessas horas a mais que os alunos permanecem na escola, há uma complementação de atividades básicas, importantes para sua formação, uma vez que os conteúdos propostos podem ser ressignificados por todos os envolvidos, culminando no processo ensino e aprendizagem, tão importante para o desenvolvimento dos educandos.

Pensar na Escola Municipal Rural Osmarina Melo de Oliveira como espaço de socialização no tocante às relações do ambiente escolar é extremamente relevante, pois crianças e adolescentes de diversas comunidades permanecem mais tempo em comunhão dentro da Balsa Escola, compartilhando ideias, trocando experiências diversas e convivendo. Assim, elas poderão construir novas formas de pensar em suas comunidades e contribuir para uma 
sociedade mais justa e democrática do campo, pois o espaço tem função educativa, que promove aprendizagens significativas, não somente para aquele dado momento, mas, sim, para uma vida.

Essas aprendizagens precisam estar voltadas ao currículo que contemple as necessidades da comunidade, como assinala o Art. 36 da Resolução Nº 4, de 13 de julho de 2010:

[...] a identidade da escola do campo é definida pela vinculação com as questões inerentes à sua realidade, com propostas pedagógicas que contemplam sua diversidade em todos os aspectos, tais como: sociais, culturais, políticos, econômicos, de gênero, geração e etnia.

Parágrafo único. Formas de organização e metodologias pertinentes à realidade do campo devem ter acolhidas, como a pedagogia da terra, pela qual se busca um trabalho pedagógico fundamentado no princípio da sustentabilidade, para assegurar a preservação da vida das futuras gerações, e a pedagogia da alternância, na qual o estudante participa, concomitante e alternadamente, de dois ambientes/situações de aprendizagem: o escolar e o laboral, supondo parceria educativa, em que ambas as partes são corresponsáveis pelo aprendizado e pela formação do estudante (BRASIL, 2010b, p. 827).

De acordo com essa citação, o currículo proposto pela Balsa Escola não atende, ao menos parcialmente, os aspectos propostos referentes à Resolução $\mathrm{N}^{\circ}$ 4, de 13 de julho de 2010, pois não se verifica a participação do estudante, concomitante e alternada em dois ambientes/situações de aprendizagem, no que se supõe uma parceria educativa, em que as partes são corresponsáveis pela formação e pelo aprendizado do estudante, bem como em relação às dificuldades enfrentadas de infraestrutura e, também, no que tange à formação de professores.

Nesse sentido, democratizar o espaço da Balsa Escola pressupõe a igualdade de acesso e permanência na escola, como enfatizam os princípios de ensino, tanto na Constituição Federal em seu artigo 208 (BRASIL, 1988), como na LDB Nº 9.394/1996, em seu artigo $3^{\circ}$ (BRASIL, 1996). Inclui, também, o sucesso a todos os que fazem parte dessa comunidade, com o objetivo de uma educação atrelada a sujeitos críticos, autônomos e conscientes de si, para melhor compreensão da sociedade em que estão inseridos, de modo que possam participar ativamente nas decisões de sua comunidade para que, assim, haja a transformação social.

\section{CONSIDERAÇÕES FINAIS}

A educação no campo, por meio de escolas de tempo integral, tem muito a proporcionar, principalmente em melhor qualidade de ensino para a população rural. A Educação Integral oferece uma jornada de tempo maior para os alunos permanecerem na escola, uma boa 
alimentação, informações sobre a saúde, a segurança, o uso de recursos tecnológicos, dentre outros conhecimentos, possibilitando espaços de aprendizagens no contexto do campo, currículo capaz de construir espaços dialógicos de justiça, igualdade, e oportunidades de acesso independentemente do local em que escolham viver ou estar.

As dificuldades encontradas na escola pesquisada, desde o trajeto de suas casas até a escola, relacionadas ao transporte, ao tempo de viagem, ao acesso aos recursos tecnológicos, dentre outras, são aspectos que interferem no andamento das atividades propostas pelos educadores. As políticas educacionais que valorizam o homem do campo ainda não se efetivaram nesse espaço educativo, encontrando limitações no processo de formação dos povos do campo.

Os saberes criados e valorizados socialmente pelos povos do campo, a cultura local e o conhecimento científico, historicamente produzido pela humanidade, devem estar atrelados ao currículo escolar das escolas do campo. Embora, do ponto de vista teórico-conceitual, não exista uma noção clara por parte da Escola sobre a diferenciação entre o tempo integral e a ampliação da jornada escolar, na prática, a instituição desenvolve uma jornada ampliada de educação. Para além das diretrizes, entende-se que há necessidade da elaboração de Currículo específico para a Balsa Escola com a participação de toda a comunidade escolar, formação e orientação para subsidiar o trabalho dos educadores e educadoras do campo que possa contribuir com o currículo escolar.

A Balsa Escola é um espaço rico e visto com muito orgulho pela sociedade humaitaense, um presente a todas as comunidades atendidas por ela e, mesmo diante das dificuldades apontadas pela pesquisa, entendemos que assim deve ser vista. Apesar disso, é um espaço de aprendizagem que carece de mais atenção dos gestores locais, de planejamento, de formação contínua para os profissionais que ali atuam na construção de uma identidade que considere as características culturais da comunidade local, que supere a educação urbana.

\section{REFERÊNCIAS}

ARROYO, Miguel Gonzáles. Ciclos de desenvolvimento humano e formação de educadores. Educação \& Sociedade, Campinas, ano XX, n. 68, p. 143-162, dez. 1999.

ARROYO, Miguel Gonzáles. Currículo, território em disputa. Petrópolis: Vozes, 2011.

BARDIN, Laurence. Análise de conteúdo. Lisboa: Edições 70, 2004. 
BRASIL. [Constituição (1988)]. Constituição da República Federativa do Brasil. Brasília, DF: Senado, 1988.

BRASIL. Decreto No 7.352, de 4 de novembro de 2010. Dispõe sobre a política de educação do campo e o Programa Nacional de Educação na Reforma Agrária - PRONERA. Diário Oficial da União: seção 1, Brasília, DF, n. 212, p. 1-3, 5 nov. 2010a.

BRASIL. Lei N 9.394, de 20 de dezembro de 1996. Estabelece as diretrizes e bases da educação nacional. Brasília: Presidência da República, Casa Civil, Subchefia para Assuntos Jurídicos, [1996]. Disponível em: http://www.planalto.gov.br/ccivil_03/leis/19394.htm. Acesso em: 20 abr. 2020.

BRASIL. Lei No 13.005, de 25 de junho de 2014. Aprova o Plano Nacional de Educação PNE e dá outras providências. Diário Oficial da União: seção 1, Brasília, DF, n. 120-A, edição extra, p. 1-7, 26 jun. 2014a.

BRASIL. Ministério da Educação. Secretaria de Articulação com os Sistemas de Ensino. Planejando a próxima década: conhecendo as 20 metas do Plano Nacional de Educação. Brasília: MEC/ SASE, 2014b.

BRASIL. Resolução CNE/CEB No 1, de 3 de abril de 2002. Institui Diretrizes Operacionais para a Educação Básica nas Escolas do Campo. Diário Oficial da União: seção 1, Brasília, DF, n. 67, p. 32, 9 abr. 2002.

BRASIL. Resolução No 4, de 13 de julho de 2010. Define Diretrizes Curriculares Nacionais Gerais para a Educação Básica. Diário Oficial da União: seção 1, Brasília, DF, n. 133, p. 824-828, 14 jul. 2010b.

BRUNO, Cristina R. C.; FORTUNATO, Sarita A. de Oliveira; MESQUIDA, Peri. O papel do pedagogo como mediador no processo ensino-aprendizagem: trabalho e crítica. In:

CONGRESSO NACIONAL DE EDUCAÇÃO - EDUCERE, 10., 2011, Curitiba. Anais eletrônicos [...]. Curitiba: PUC-PR, 2011. Disponível em:

https://educere.bruc.com.br/CD2011/pdf/5655_2867.pdf. Acesso em: 27 jun. 2020.

CALDART, Roseli Salete. Por uma educação do campo: traços de uma identidade em construção. In: KOLLING. Edgar Jorge; CERIOLI, Paulo Ricardo; CALDART, Roseli Salete (Orgs.). Educação do campo: identidade e políticas públicas. Brasília, DF: Articulação Nacional por uma educação do campo, 2002. p. 18-25.

CAVALIERE, Ana Maria. Em busca do tempo de aprender. Cadernos Cenpec, São Paulo, v. 1, n. 2, p. 91-101, 2006. DOI: http://dx.doi.org/10.18676/cadernoscenpec.v1i2.130.

CAVALIERE, Ana Maria. Educação Integral: uma nova identidade para a escola brasileira? Educação \& Sociedade, Campinas, v. 23, n. 81, p. 247-270, dez. 2002.

CHIZZOTI, Antonio. Pesquisa em Ciências Humanas e Sociais. 4. ed. São Paulo: Cortez, 2000. 
DUBET, François. O que é uma escola justa? A escola das oportunidades. São Paulo: Cortez, 2008.

FERRAZ, João Baptista Silva et al. Amazônia: características e potencialidades. In: HIGUCHI, Maria Inês Gasparetto; HIGUCHI, Niro. A Floresta Amazônica e suas múltiplas dimensões: uma proposta de educação ambiental. 2. ed. Manaus: [s.n.], 2012. p. 13-40.

FRANCO, Zilda Gláucia Elias. Um olhar sobre as escolas localizadas no campo do Município de Humaitá (Sul do Amazonas): em busca da justiça curricular. Orientadora: Branca Jurema Ponce. 2018. 205 f. Tese (Doutorado em Educação: Currículo) - Pontifícia Universidade Católica de São Paulo, São Paulo, 2018.

FREIRE, Paulo. A educação na cidade. 6. ed. São Paulo: Cortez, 2005.

GONÇALVES, Antonio Sérgio. Reflexões sobre educação integral e escola de tempo integral. Cadernos Cenpec, São Paulo, v. 1, n. 2, p. 129-135, 2006. DOI: http://dx.doi.org/10.18676/cadernoscenpec.v1i2.136.

HUMAITÁ. Embarcação Base Educacional Irmã Angelica Tonetta. NB-Engenharia e Construtora LTDA-ME. Engenheiro naval responsável: Anderson Dantas. Porto Velho - RO, 2014.

HUMAITÁ. Lei Municipal No 679, de 12 de maio de 2015. Cria os polos-base de educação do Município de Humaitá-AM, e dá outras providências. Diário Oficial dos Municípios de Estado do Amazonas: Manaus, AM, ano VI, n. 1360, p. 8-9, 28 maio 2015.

HUMAITÁ. Programação Anual Balsa Escola. Humaitá: Secretaria Municipal de Educação, 2016.

HUMAITÁ. Regimento interno da Escola Osmarina Melo de Oliveira. Humaitá: Secretaria Municipal de Educação, 2019.

IBGE. Instituto Brasileiro de Geografia e Estatística. Estimativas de população. 2018. Disponível em: https://www.ibge.gov.br/estatisticas-novoportal/sociais/populacao/9103estimativas-de-populacao.html?=\&t=resultados. Acesso em: 5 mar. 2019.

IBGE. Instituto Brasileiro de Geografia e Estatística. Amazonas: população. 2019. Disponível em: https://cidades.ibge.gov.br/brasil/am/panorama. Acesso em: 20 abr. 2020.

OBSERVATÓRIO DO PNE. O Plano Nacional de Educação. 2018. Disponível em http://www.observatoriodopne.org.br/metas-pne/6-educacao-integral. Acesso em: $17 \mathrm{de}$ fev. 2018.

MARQUES, Saray. Tempo escolar estendido: Análise do Programa Ensino Integral (PEI) da Secretaria de Estado da Educação de São Paulo (SEE-SP) Gestão Geraldo Alckmin (2011 - 
2017). Orientadora: Branca Jurema Ponce. 2017. 188 f. Tese (Doutorado em Educação:

Currículo) - Pontifícia Universidade Católica de São Paulo, São Paulo, 2017.

OLIVEIRA, Dalila Andrade. A reestruturação do trabalho docente: precarização e flexibilização. Educação \& Sociedade, Campinas, v. 25, n. 89, p. 1127-1144, set./dez. 2004.

PIRES, Angela Monteiro. Educação do Campo como direito humano. São Paulo: Cortez, 2012.

PONCE, Branca Jurema; FRANCO, Zilda Gláucia Elias. Em busca de uma prática curricular inclusiva e mais justa: ampliando o olhar sobre os direitos. In: SIMPÓSIO BRASILEIRO DE POLÍTICA E ADMINISTRAÇÃO DA EDUCAÇÃO. Estado, políticas e gestão da educação: tensões e agendas em (des)construção, 28., 2017, João Pessoa. Anais [...]. João Pessoa: Universidade Federal da Paraíba, 2017. p. 3131-3135.

TIRONI, Margarete; GOMES, Aurélia Lopes. Educação de Tempo Integral na Escola do Campo: questões curriculares e a perspectiva interdisciplinar. In: CONGRESSO NACIONAL DE EDUCAÇÃO: EDUCERE, 11., 2013, Curitiba. Anais eletrônicos [...]. Curitiba: PUCPR, 2013. Disponível em: https://educere.bruc.com.br/CD2013/pdf/8804 4773.pdf. Acesso em: 7 abr. 2020.

TRIVIÑOS, Augusto Nibaldo Silva. Introdução à pesquisa em ciências sociais: a pesquisa qualitativa em Educação. São Paulo: Atlas, 1987.

\section{NOTAS}

${ }^{1}$ Este texto faz parte do trabalho de campo desenvolvido durante a pesquisa de Doutorado intitulada Um olhar sobre as escolas localizadas no campo do Município de Humaitá (Sul do Amazonas): em busca da justiça curricular (FRANCO, 2018), que se insere no âmbito do Grupo de Educação e Pesquisa em Justiça Curricular GEPEJUC da Pontifícia Universidade Católica de São (PUC-SP) e, também, de pesquisas desenvolvidas no Núcleo de Estudos e Pesquisas em Direitos Humanos e Educação (NEPDHE) da Universidade Federal do Amazonas (UFAM).

${ }^{2}$ A Balsa Escola é a única no país que atende a crianças e a adolescentes na Educação Básica.

${ }^{3}$ A análise do número de matrículas que vem ocorrendo na balsa escola mais o número de servidores que trabalham e moram na embarcação levantou uma alerta com relação à capacidade total de pessoas que podem ser agrupadas na balsa. $\mathrm{O}$ documento da embarcação refere-se a 160 pessoas (tripulação e passageiros). A informação necessita de estudos mais rigorosos.

${ }^{4}$ Além das questões curriculares, o ambiente escolar apresenta dificuldade relacionada à presença de um inseto conhecido como Potó (termo originário do Tupi), cientificamente o Paederus. O inseto parece com uma formiga e costuma aparecer no final do período chuvoso. Quando está começando o calor, ele é atraído pela claridade e solta uma secreção tóxica que provoca a queimadura quando se choca com a pele. A toxina que eles liberam é uma forma de defesa. Uma das coordenadoras da SEMED explicou que muitas crianças estão marcadas com a queimadura pela picada do inseto e que os pais vão até a secretaria reclamar, porém não há o que fazer, a não ser orientar com o cuidado ao sentar-se ou encostar nos móveis.

Recebido em: 15/05/2020

Aprovado em: 29/07/2020

Zilda Gláucia Elias FRANCO, Eulina Maria Leite NOGUEIRA, Saray MARQUES Balsa escola: educação de tempo integral em uma escola localizada no campo em Humaitá no estado do 